\title{
LATENT NYSTAGMUS AND ALTERNATING HYPERPHORIA $\dagger$
}

\author{
BY \\ J. RINGLAND ANDERSON \\ Melbourne, Australia
}

\begin{abstract}
AmONGST 34,000 patients, 138 were found with congenital nystagmus, of whom at least twenty showed the form known as "latent nystagmus". Of these, thirteen were classed as typical (Table). The nature and origin of this uncommon condition is a mystery. A curious fact was revealed in this study: all the patients with this form of nystagmus had another mysterious condition-alternating hyperphoria or "sursumduction". It is thought that an explanation of this association may throw light on the normal development and nature of the reflexes that underlie perfect oculomotor control. Let us first of all briefly consider the knowledge we have of the former condition.
\end{abstract}

\section{Latent Nystagmus}

This is an uncommon and unexplained condition, wherein nystagmus, not normally present with both eyes open, becomes manifest on occlusion of one eye and, as a rule, on conjugate deviation. The nystagmus is usually rhythmic in nature. Close observation reveals that the initial movement on occlusion is a slow one towards the obstructed eye*. In conjugate deviation the slow component is away from the side looked at.

This condition is probably closely related to cases of constant nystagmus which are more marked on covering one eye. As Sorsby (1931) pointed out, previous writers have included under the heading "latent nystagmus":

(i) cases with no sign of nystagmus with both eyes open, even in the extreme positions of rotation;

(ii) cases with nystagmus with both eyes open and when convergent or in conjugate deviation;

(iii) cases which usually show nystagmus with both eyes open, but none on converging or on fixing an object (Faucon's case, quoted by Sorsby, 1931).

\section{Characteristics}

Age of Onset.- One assumes that this condition appears at the age at which certain associated reflexes are normally called on to function. To prove this, routine observations of eye movements on alternate occlusion would be necessary. The earliest age at which it was recognized in the present series was 19 months. It is of interest that recorded patients are almost all young. The eldest of Sorsby's five patients was 26, and the eldest of my twenty patients was 32 years old. Those patients who have been followed for a period of 5 years show no reduction of the alternating hyperphoria though the latent nystagmus in some may be less marked.

† Received for publication September 2, 1953

*The form of obstruction necessary to elicit nystagmus varies. In addition to the usual form of occlusion, sometimes high spheres, prisms, or tinted glass before one or both eyes suffice. 
TABLE.

ANALYSIS OF

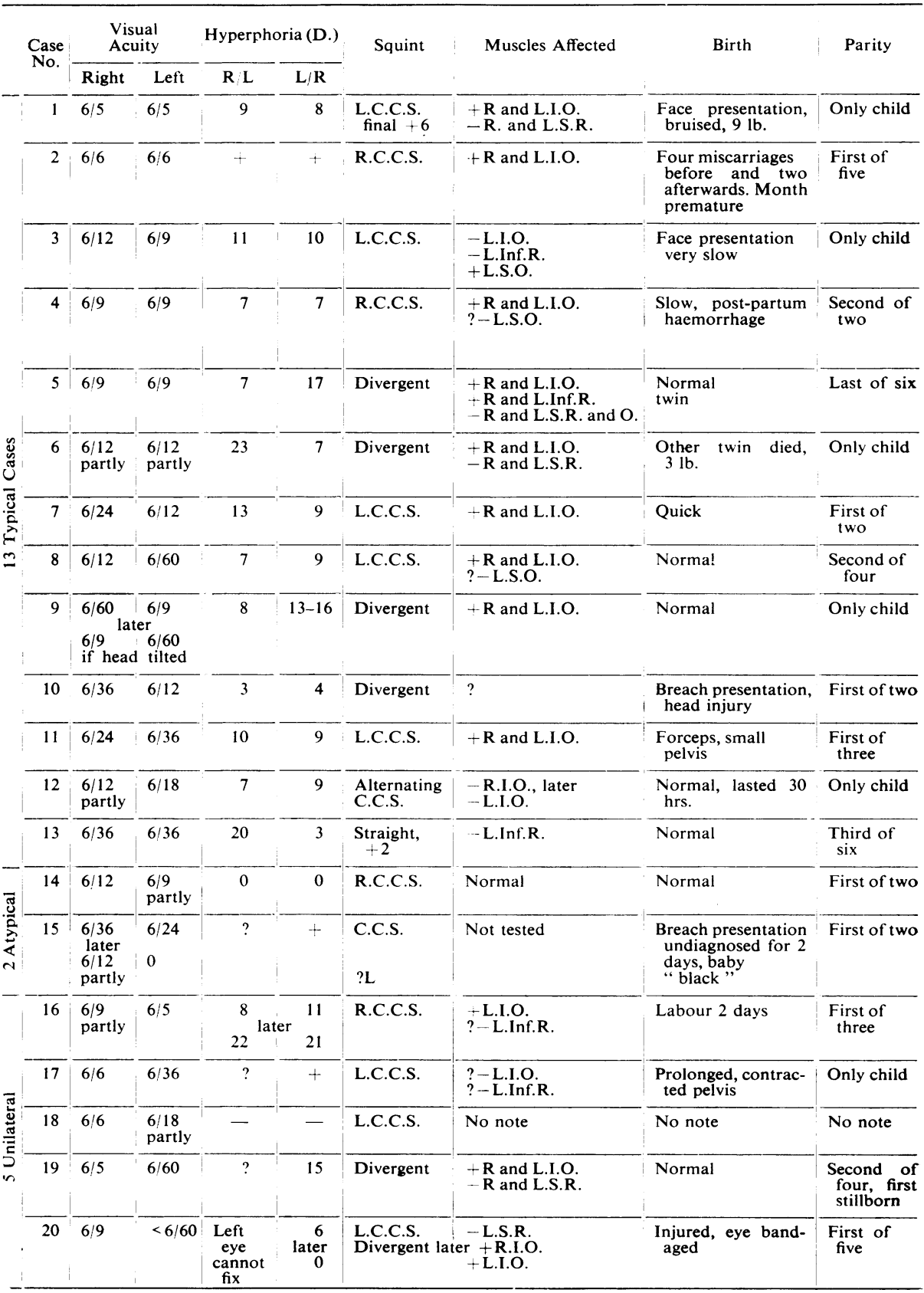




\section{TWENTY CASES}

\begin{tabular}{|c|c|c|c|c|c|}
\hline \multirow{2}{*}{ Eyes Front } & \multicolumn{2}{|c|}{ Conjugate Deviation } & \multicolumn{2}{|c|}{ Occlusion } & \multirow{2}{*}{$\begin{array}{l}\text { Fusion and } \\
\text { Correspondence }\end{array}$} \\
\hline & To Right & To Left & Of Right & Of Left & \\
\hline Nil & Clockwise & Anti-clockwise & $\begin{array}{l}\text { Anti-clockwise, later } \\
\text { rhythmic }\end{array}$ & $\underset{\text { nil }}{\text { Clockwise later }}$ & Abnormal \\
\hline Nil & $\begin{array}{l}\text { Rhythmic and } \\
\text { rare slow rota- } \\
\text { tion }\end{array}$ & $\begin{array}{l}\text { Rhythmic and } \\
\text { rare slow rota- } \\
\text { tion }\end{array}$ & Rhythmic, horizontal & $\begin{array}{l}\text { Rhythmic, } \\
\text { horizontal }\end{array}$ & Poor fusion \\
\hline $\begin{array}{l}\text { Nil, sometimes } \\
\text { slight rotatory }\end{array}$ & $\begin{array}{l}\text { Anti-clockwise } \\
\text { abducted eye } \\
+\end{array}$ & Clockwise & Rhythmic, horizontal & $\begin{array}{l}\text { Rhythmic, } \\
\text { horizontal }\end{array}$ & $\begin{array}{l}\text { Absent } \\
\text { Some fusion }\end{array}$ \\
\hline $\begin{array}{l}\text { Nil, sometimes } \\
\text { slight clockwise }\end{array}$ & $\begin{array}{l}\text { Slight anti- } \\
\text { clockwise and } \\
\text { horizontal of } \\
\text { abducted eye + }\end{array}$ & Slight clockwise & Rhythmic, horizontal & $\begin{array}{l}\text { Rhythmic, } \\
\text { horizontal }\end{array}$ & Absent \\
\hline Nil & $\begin{array}{l}\text { Fine } \\
\text { Left moves }\end{array}$ & $\begin{array}{l}\text { Fine } \\
\text { Left moves }\end{array}$ & Rhythmic, horizontal & $\begin{array}{c}\text { Rhythmic, } \\
\text { horizontal }\end{array}$ & Good with stereo \\
\hline$\underset{\text { horizontal }}{\text { Nil or slight }}$ & Slight rotatory & $\begin{array}{l}\text { Fine, rhythmic, } \\
\text { and slight ro- } \\
\text { tatory }\end{array}$ & Rhythmic, horizontal & $\begin{array}{l}\text { Rhythmic, } \\
\text { horizontal }\end{array}$ & Absent \\
\hline Nil & Nil & Rhythmic & Rhythmic, horizontal & $\begin{array}{l}\text { Rhythmic, } \\
\text { horizontal }\end{array}$ & Abnormal \\
\hline Nil & Nil & Nil & Rhythmic, horizontal & $\begin{array}{c}\text { Rhythmic, } \\
\text { horizontal }\end{array}$ & Few degrees \\
\hline $\begin{array}{c}\text { Fine, horizontal, } \\
\text { sometimes nil }\end{array}$ & Coarse rhythmic & Fine rhythmic & Rhythmic, horizontal & $\begin{array}{c}\text { Rhythmic, } \\
\text { horizontal }\end{array}$ & No fusion \\
\hline Nil & Nil & Nil & $\begin{array}{l}\text { Rhythmic and on } \\
\text { convergence }\end{array}$ & $\begin{array}{c}\text { Rhythmic, } \\
\text { horizontal }\end{array}$ & No note \\
\hline Nil & Rhythmic slow & $\begin{array}{c}\text { Rhythmic fine } \\
\text { and fast }\end{array}$ & Rhythmic, horizontal & $\begin{array}{c}\text { Rhythmic, } \\
\text { horizontal }\end{array}$ & Absent \\
\hline $\mathrm{Nil}$ & ? Nil & Rhythmic & Rhythmic, horizontal & $\begin{array}{c}\text { Rhythmic, } \\
\text { horizontal }\end{array}$ & Good \\
\hline $\begin{array}{l}\text { Nil or slight } \\
\text { horizontal }\end{array}$ & Rhythmic coarse & Rhythmic fine & Rhythmic, horizontal & $\begin{array}{c}\text { Rhythmic, } \\
\text { horizontal }\end{array}$ & Good with stereo \\
\hline $\begin{array}{llr}\text { Very } & \text { fine, } & 6 \\
\text { years } & \text { later } & \text { nil }\end{array}$ & Fine and fast & Coarse & Rhythmic & Marked & Fair with stereo \\
\hline 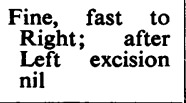 & Coarse & Fine & $\begin{array}{l}\text { Not tested till Left } \\
\text { excision then slight }\end{array}$ & $\begin{array}{l}\text { Not tested till } \\
\text { Left excision } \\
\text { then nil }\end{array}$ & No note \\
\hline $\begin{array}{l}\text { Nil or slight } \\
\text { irregular of } \\
\text { Right only }\end{array}$ & $\begin{array}{l}\text { Slight rhythmic } \\
\text { horizontal of } \\
\text { Right }\end{array}$ & $\begin{array}{l}\text { Very slight of } \\
\text { Right }\end{array}$ & Nil & Slight & Normal, no range \\
\hline Nil & Rhythmic & Rhythmic & Nil & Rhythmic & Left amblyopic \\
\hline Nil & No note & No note & Rhythmic & ? Nil & Left amblyopic \\
\hline Nil & $\begin{array}{l}\text { Fine and fast: } \\
5 \text { years later nil }\end{array}$ & $\begin{array}{l}\text { Coarse, } 5 \text { years } \\
\text { later nil }\end{array}$ & $\begin{array}{l}\text { Coarse rhythmic Right } \\
\text { turns up }\end{array}$ & Nil & Left amblyopic \\
\hline $\begin{array}{l}\text { Slight horizontal } \\
\text { or nil. None } \\
\text { for near }\end{array}$ & $\begin{array}{cl}\text { Very } & \text { fine (or } \\
\text { nil) } & \text { rhythmic }\end{array}$ & Coarse $\mathbf{L}>\mathbf{R}$ & $\begin{array}{l}\text { Rhythmic } \\
\text { (Left has no } \mathrm{f}\end{array}$ & $\begin{array}{l}\text { Nil } \\
\text { ixation) }\end{array}$ & Left amblyopic \\
\hline
\end{tabular}


Inheritance.-As far as I could ascertain in this series, there was no instance of more than one member in a family being affected. Neither have I been able to find a report in the literature of such an occurrence. Certain reports however have not been available. One patient in my series had a sister with alternating hyperphoria but no nystagmus. Each had had a difficult birth.

Visual Acuity.-There is great variation in the patients in this series:

(1) $6 / 12$ or better in each eye, eight patients: $6 / 12,6 / 9 ; 6 / 9,6 / 9 ; 6 / 9 p, 6 / 5 ; 6 / 6,6 / 6 ; 6 / 12 p, 6 / 12 p ; 6 / 5,6 / 5 ; 6 / 6,6 / 6 ; 6 / 6,6 / 12 p$.

(2) $6 / 12$ or better in only one eye, seven patients: $6 / 24,6 / 12 ; 6 / 12,6 / 60 ; 6 / 60,6 / 9 ; 6 / 36,6 / 12 ; 6 / 9,6 / 60 ; 6 / 5,6 / 60 ; 6 / 6,6 / 36$.

(3) Less than $6 / 12$ in each eye, five patients: $6 / 24,6 / 36 ; 6 / 12 p, 6 / 18 ; 6 / 36,6 / 36 ; 6 / 36,6 / 24 ; 6 / 36,6 / 24$.

The upward rotation does not vary with the defect in vision. Neither does the worse eye necessarily show the greater upward turn. For example:

(1) The greatest upward rotation in this series was $\mathrm{R} / \mathrm{L} 23$, when one eye with $6 / 12$ partly was fixing, and the least was $\mathrm{R} / \mathrm{L} 3$, when the other eye also with $6 / 12$ partly was fixing.

(2) Another patient had L/R 13-16 when the right eye with 6/9 was fixing, and R/L 8 when the left eye was fixing with $6 / 60$.

Kestenbaum (1946) wrote " if one eye is removed the nystagmus of the remaining eye persists as a permanently visible nystagmus, which may gradually decline in intensity". Fromaget (quoted by Sorsby, 1931) reported such a case. One patient of mine (Case 15) was an exception to this rule for his constant fine nystagmus disappeared when he lost one eye. It appears that vision does not play a great part, for in some cases covering the better eye and in others covering the worse eye, leads to greater nystagmus (Sorsby, 1931). Acuity varies from 6/5 to 6/60.

The visual acuity may be lessened by the nystagmus. In one of our patients the vision of each eye separately was 6/24 and binocularly 6/6. Manual fixation of the globe may improve vision.

Retinal Correspondence and Fusion.--Retinal correspondence was either absent or abnormal in eight cases $(1,3,4,6,7,11,17,18)$.

Fusion was absent in these cases, except 3 , and in two other cases $(9,20)$. It was poor in five $(2,3,16,8,14)$, and good with stereopsis in three $(5,12,13)$. It was not tested in the remaining one (10).

Associated Motor Defects.-Strabismus was present in all except one of my cases. In eleven it was convergent and in five divergent, an unusually large proportion for the latter.

Overaction of both inferior oblique muscles was shown in eleven cases:

Four cases showed underaction of one or both superior rectus muscles, and one showed underacting superior rectus and superior oblique muscles and overactive inferior rectus muscles.

In two cases one inferior oblique and one inferior rectus muscle appeared to be weak.

In one case one inferior oblique muscle overacted and the inferior rectus appeared to be weak.

In one case both inferior oblique muscles were weak.

In one case one inferior rectus appeared to be weak. 
Only one patient (15) appeared to have full versions. It was significant that he was the only more or less typical case that had no alternating hyperphoria (14). The versions of the remaining two were unknown $(10,18)$.

The most important associated muscular anomaly however was the condition known as alternating hyperphoria.

Causes.-There was no consanguinity and no obvious sign of inheritance in this series.

Difficulties at Birth.-The incidence was high.

1, face presentation, face bruised, $9 \mathrm{lb}$.;

2 , face presentation, very slow;

3 , one month premature, preceded by four miscarriages and followed by two before the next baby, also premature;

4, slow followed by severe haemorrhage;

6 , weighed $3 \mathrm{lb}$., one of twins, other died;

10 , breach presentation, forceps, head injury;

20 , injuries at birth, eye bandaged;

15 , breach, undiagnosed for 2 days, " baby black",

17 , much delayed, pelvis contracted.

In six cases the labours were described as " normal". In at least three other patients who were primiparous, forceps were used, after 30 , and $48 \mathrm{hrs}$, and an unknown period. Of the last the doctor wrote " the pelvic outlet was observed to be narrow and probably more force than usual would have been necessary". So nine births were difficult, six were " normal ", three were possibly so, and the nature of one (18) was unknown. There is a possibility that undue pressure or anoxaemia may have occurred even in a labour described years later as "normal". Two of the patients were unrelated twins. The second twin in one instance had died at birth and in the other instance was normal and of opposite sex.

Parity.

$\begin{array}{lllll}\text { Only labour } & 6 & \text { First of five labours } & 2 & \text { Third of six labours } 1 \\ \text { First of two labours } & 4 & \text { Second of two labours } & 1 & \text { Last of six labours (twins) } 1 \\ \text { First of three labours } 2 & \text { Second of four labours } 2 & \text { Unknown }\end{array}$

Occlusion.-In the common constant form of congenital nystagmus the movements are not usually increased by occlusion and sometimes they are lessened. This is in marked contrast with its influence in latent nystagmus.

It was interesting to observe the effect of occlusion in a patient with constant congenital nystagmus and hippus. In frontal gaze there were fast fine clockwise rotatory movements, the right eye moving more than the left. These movements were increased on looking to the right and became fine and horizontal on looking to the left. Covering the right eye $(R \mathrm{~V}=6 / 24)$ increased the movements, and the rate of the hippus, and covering the left eye $(\mathrm{L} V=6 / 9)$ slowed the nystagmus and lessened the hippus. On looking up or down the nystagmus became horizontal. The face was turned to the right to improve vision though no position of rest was found. The patient was the first of three children. The labour (in 1921) was described as being instrumental and very bad, the mother being kept in hospital for 6 weeks after delivery.

Various Stimuli.-There are two typical means of revealing latent nystagmus:

(1) Covering one eye. 
(2) Conjugate deviation. This failed to produce nystagmus in two of the otherwise typical cases $(8,10)$; in two others it failed towards one side only $(7$, and possibly 12 ).

In addition, the following methods are sometimes adequate:

(3) Shades of varying intensity over one eye.

(4) High convex lens before one eye.

(5) High convex lenses before both eyes.

(6) Prisms before one or both eyes.

Contradictory results.

(7) Convergence may lessen the nystagmus, but in some cases has increased it (Fromaget and Dorff, quoted by Sorsby, 1931).

(8) Covering part of the field especially the macular region (Kestenbaum, 1946), bar-reading or on looking towards the nose.

(9) A bright light shining into one eye.

\section{Responses}

(1) On occlusion, the nystagmus is nearly always rhythmic with the slow component towards the covered eye. On conjugate deviation rhythmic nystagmus is more common than rotatory nystagmus. On conjugate deviation the slow component appears to be away from the side looked at. Sometimes close observation is necessary if one is to see this initial slow movement. It is comparable with the rare condition called "latent deviation" Kestenbaum (1946), in which, when one eye has very poor vision, covering the better eye leads to a deviation but not nystagmus. Kestenbaum considers that the eyes do not return from this position because the impulse from the weak eye is insufficient. The open eye rotates inwards towards the covered eye and the covered one is abducted and no nystagmus occurs.

(2) The ocular movements of the typical cases in this series may be summarized as follows:

\begin{tabular}{|c|c|c|c|c|}
\hline \multirow{2}{*}{ Position } & \multirow{2}{*}{\multicolumn{2}{|c|}{ Movements }} & \multicolumn{2}{|c|}{ Type of Movement } \\
\hline & & & Rotary & Rhythmic \\
\hline Frontal & $\begin{array}{l}\text { Nil } \\
\text { Sometimes slight }\end{array}$ & $\begin{array}{l}8 \\
5\end{array}$ & 2 & 3 \\
\hline To right & $\begin{array}{l}\text { Present } \\
\text { Mixed } \\
\text { Nil }\end{array}$ & $\begin{array}{l}9 \\
2 \\
4\end{array}$ & 3 & 4 \\
\hline To left & $\begin{array}{l}\text { Present } \\
\text { Mixed } \\
\text { Nil }\end{array}$ & $\begin{array}{r}11 \\
2 \\
2\end{array}$ & 3 & 6 \\
\hline Right occlusion & $\begin{array}{l}\text { Present } \\
\text { Mixed } \\
\text { Nil }\end{array}$ & $\begin{array}{r}13 \\
0 \\
0\end{array}$ & 1 & 12 \\
\hline Left occlusion & $\begin{array}{l}\text { Present } \\
\text { Mixed } \\
\text { Nil }\end{array}$ & $\begin{array}{r}13 \\
0 \\
0\end{array}$ & 1 & 12 \\
\hline
\end{tabular}

The number of patients with rotatory movements in this series is worthy of note. All except one of them changed to horizontal movements on occlusion. As the majority of patients in this series had defective balance of the oblique muscles it is likely that such imbalance can explain the frequency of these rotatory movements round the antero-posterior axis. 
Variability.-Is latent nystagmus an entity?

It appears that there is no hard and fast line between latent and ordinary congenital nystagmus. Van der Hoeve (1918) reported a man with constant nystagmus which became latent. In the author's series of cases with constant congenital nystagmus there were some in which the nystagmus with both eyes open was so slight as to be scarcely visible. It is known that congenital constant nystagmus may disappear, and the question must be asked whether latent nystagmus may disappear, for it is variable and the patients reported are usually under 33 years: It appears that fatigue plays a part in producing nystagmus, and not infrequently once the movements have been produced they may persist for a time in frontal vision.

Several patients with latent nystagmus displayed fine horizontal movements in the frontal position when fatigued. The most interesting was Case 9, regarding whom several points deserve attention:

(a) When not fatigued the patient showed nystagmus only on obscuring either eye, or on placing $+2 \cdot 00 \mathrm{D} \mathrm{sph}$. before both, or on conjugate deviation to either side. His angle with the right eye fixing at $0^{\circ}$, was $-5^{\circ} \mathrm{L} / \mathrm{R} 13-16$, and with the left eye fixing at $0^{\circ}$, $-5^{\circ} \mathrm{R} / \mathrm{L} 8$.

(b) When fatigued the nystagmus became constant, the movements being least on looking up to the left. This was opposite to his head-position of choice, viz. head towards right shoulder and chin down. The nystagmus was almost as much reduced on looking down to the right.

(c) When he was first examined he was 7 years old and vision in the-right eye with $+1 \cdot 0$ D.sph. was $6 / 60$ and in the left eye with $+2 \cdot 5$ D.sph. and +3.0 D.cyl. 6/9;18 months later the vision in the right eye was $6 / 60$ with $+2.0 \mathrm{D}$.sph. and in the left eye $6 / 6$ with +3.5 D.sph. and +3.0 D.cyl. For this reading his face was turned to the right and his head slightly tilted towards the left shoulder.

He was not examined again until the age of 14 years, when the vision in the right eye was $6 / 60$ with head straight, but $6 / 6$ partly with his face to the right and chin down. The left eye with -1.0 D.sph. and $+3 \cdot 0$ D.cyl. read only $6 / 36$, and was not improved in any direction. What caused the reversal in vision?

(d) It was interesting to observe that the upward deviation was less when the good eye was fixing (viz. R/L 8) than when the poor eye was fixing (L/R 13-16).

Not only the nystagmus but also the alternating hyperphoria may vary from visit to visit.

Case 11, aged 7

$$
\begin{array}{ll}
\text { 30.1.53 } & \begin{array}{l}
\text { Right eye fixing at } 0^{\circ} \times=10^{\circ} \mathrm{L} / \mathrm{R} \quad 8 ; \\
\text { Left eye fixing at } 0^{\circ} \times=7^{\circ} \mathrm{R} / \mathrm{L} 10
\end{array} \\
\text { 13.5.53 } & \begin{array}{l}
\text { Right eye fixing at } 0^{\circ} \times 7^{\circ} \mathrm{L} / \mathrm{R} 8 ; \\
\text { Left eye fixing at } 0^{\circ} \times 6^{\circ} \mathrm{R} / \mathrm{L} 10
\end{array} \\
\text { 13.7.53 } & \begin{array}{l}
\text { Right eye fixing at } 0^{\circ} \times 7^{\circ} \mathrm{L} / \mathrm{R} 7 ; \\
\text { Left eye fixing at } 0^{\circ} \times=9^{\circ} \mathrm{R} / \mathrm{L} 1 .
\end{array}
\end{array}
$$

Though there is variability, and transition occurs from typical latent to constant nystagmus, the characteristics of the former are sufficiently definite to warrant its consideration as a separate entity. Not every case is identical, but the more closely we examine any abnormal condition the more slight variations from its typical features will be found. 
The essential feature of this type of congenital nystagmus is its appearance on occlusion; in addition it is closely associated with alternating hyperphoria, imbalance of the oblique muscles, and a rotatory type of nystagmus.

Other forms of congenital nystagmus rarely increase on occlusion, nor are they associated with alternating hyperphoria.

\section{Atypical Cases}

Case 14, aged 22, clerk, developed convergent strabismus after whooping cough, when 2 years old. Visual acuity in the right eye 6/9; in the left 6/6. Nystagmus: Frontal, nil; to right, fine rhythmic, fast to right; to left, coarser, fast to left. To either side the adducted eye shows less nystagmus. Right occlusion produces slight rhythmic movements which cease on fixation. Left occlusion shows marked rhythmic nystagmus, fast to left! His cptico-kinetic nystagmus is slight but normal. With right eye fixing at $0^{\circ}$, his angle is $+4 \mathrm{R} / \mathrm{L} 0$. With left eye fixing at $0^{\circ}$, his angle is $+3 \mathrm{R} / \mathrm{L} 0$. Fusion from $-4^{\circ}$ to $+15^{\circ}$. Fair stereopsis. Versions normal.

This case is unusual because the patient has no alternating hyperphoria. On alternate occlusion either eye swings in but not upwards. It appeared as if this marked esophoria might suppress sursumduction, but when the esophoria was corrected with prisms none was revealed. Nystagmus on occlusion was more marked when the patient was wearing glasses. Convergence produced a slight nystagmus. The left eye was strongly dominant.

Case 15, $4 \frac{1}{2}$ years old when first seen, had had a convergence and nystagmus all his life. After a breach presentation, unrecognized for 2 days, he was "black" at birth and the doctor said that " it was a miracle that he was alive". Visual acuity was $6 / 36$ in the right eye and 6/24 in the left. Nystagmus-frontal-very fine, fast to right, increased on covering either eye. To right-coarse, fast to right; to left-finer, fast to left. No note regarding hyperphoria wảs made.

At $7 \frac{1}{2}$ years the left eye was lost after an accident. At 13 years there was no nystagmus. in the frontal position but coarse nystagmus to the right and less to the left. On occlusion of the right eye the prosthesis rotated upwards slightly! He had apparently developed latent nystagmus after excision of the better eye. This is the reverse of Fromaget's case in which nystagmus became constant after the loss of one eye. Is the difference due to the dominance of the eye that is lost? In this case the better eye was lost. Unfortunately we do not know if the alternating hyperphoria existed before the loss of one eye.

Sorsby (1931) pointed out that no reported case showed greatest nystagmus in the position of adduction, but that nystagmus was greatest in abduction in some patients and in the central position in others. The movement appeared to lessen if the uncovered eye was adducted, that is, if it looked in the direction of the slow component. Cases have been reported in which there was "spring nystagmus" when one eye was covered, but "oscillatory" nystagmus when both eyes were open.

It is of value to realize that frequently the unbalanced tone that produces a slight rotatory movement in the central position or even on conjugate deviation is subjugated to a more powerful horizontal stimulus on occlusion. This stimulus leads to the characteristic slow movement towards the opposite side and is followed by the fast recovery that produces the rhythmic character.

An example of this is Case 4. On frontal gaze there was either no movement or very slight clockwise rotation; to the right slight horizontal and anticlockwise rotation, and to the left slight clockwise rotation developed, but on occlusion the movements became rhythmic (cf. also Case 14). 


\section{Unilateral Nystagmus}

In this condition either covering one eye only or conjugate deviation in one direction produces nystagmus. Both eyes move, though not necessarily to an equal degree.

Cases 19 and 17 showed rhythmic nystagmus on covering the better eye only (visual acuity right eye $6 / 5,6 / 5$; left eye $6 / 36$ and $6 / 60$ ) and on conjugate deviation. In the former the movements were fine to the right and coarse to the left.

Case 18 showed nystagmus on covering the better eye (visual acuity, right eye 6/6; left eye $6 / 12$ partly). No note about conjugate deviation.

Case 20 usually showed no nystagmus on frontal gaze, but if he was tired fine movements appeared. Looking to the right movements were fine, but on looking to the left coarse. Covering the right eye (visual acuity 6/9) led to increased nystagmus, but when the left eye (visual acuity 6/60) was covered no nystagmus was seen.

$$
\begin{array}{r}
\text { Right eye fixing at }-15^{\circ} \text {, angle }-13 \mathrm{~L} / 8 . \\
0^{\circ} \text {, angle }-10 \mathrm{~L} / 6 . \\
+15^{\circ} \text {, angle }-10 \mathrm{~L} / 4 .
\end{array}
$$

Left eye unable to fix.

Case 16 did not have nystagmus on covering the right eye. At other times only the left eye appeared to move.

\section{Alternating Hyperphoria (Alternating Sursumduction)}

Every case of true latent nystagmus in this series, with one exception (14), showed a varying degree of alternating hyperphoria. In the unilateral form, and in constant congenital nystagmus, upward rotation on occlusion was not observed.

Since confusion exists regarding the term "alternating hyperphoria", let us briefly consider the position. Verhoeff (1941) advocated the use of the name " occlusion hypertropia", but since it appears to the author that phoria is at present the familiar title, the name "alternating hyperphoria" is used here.

There are three objections to the use of the term "hyperphoria" according to Verhoeff:

(a) In true hyperphoria one eye shows an upward deviation when not fixing and its fellow a downward deviation if it be covered.

(b) In true hyperphoria, not complicated by strabismus, the upward deviation is due to the removal of bifixation, while in this condition this may not be so. The real anomaly is the same whether bifixation exists or not. In a few typical cases the deviation of one eye under cover has been first measured with prisms. Then, neither eye being covered, a rotary prism has been rotated before this eye until the base-up prismatic effect is such that its consequent downward deviation is replaced by an upward rotation. Usually then, if the condition is one of "occlusion hypertropia ", this eye will rotate further upwards if occluded. This additional upward deviation was not due to the release of bifixation.

(c) When " occlusion hypertropia " is present with strabismus, the upward deviation is not exhibited until one eye is covered, though the existence of strabismus itself prevents bifixation.

It seems to the author that the first objection is overcome by the term " alternating hyperphoria ", meaning a condition in which an upward deviation of either 
eye is present, if the eye is not fixing, not simply an upward deviation of one eye with a downward rotation of the other when not fixing. In spite of objections $(a)$ and $(b)$ the author prefers to use " hyperphoria ", because it contains the idea of a latent upward deviation rather than the idea of a "tropia" obvious under normal conditions.

There appear to be $t w o$, possibly three conditions:

(1) A simple isolated upward turning of each eye separately under cover. This is symptomless and requires no troatment. There is no sign of paresis. Chavasse considered that it was a return to the position of absolute rest-upward and outwards-the reflex response to the stimulation of one retina being insufficient to effect that which is normally achieved by the stimulation of both retinae. Scobee (1952) supported this conception, but preferred the term "alternating sursumduction".

(2) Scobee emphasized the need to distinguish " double hyperphoria " from alternating sursumduction. When upward rotation of either eye occurs under cover in the presence of some evidence of muscular imbalance, such as overaction or underaction, then a pathological condition-" double hyperphoria "-exists, which may require treatment.

(3) This condition is not infrequently present with a double vertical strabismusalternating hypertropia. Bilateral paresis of the depressors can account for this. The deviation or squint that results is seen in binocular vision, but its increase on alternate occlusion shows the additional hyperphoria.

Are we then to consider three separate states?

(1) Alternating Sursumduction.-Upward deviation of either eye occurring when binocular vision is interfered with and in the absence of any muscular imbalance.

(2) Alternating Hyperphoria.-Similar upward deviation of either eye associated with even the least muscular imbalance, overaction of the inferior oblique muscles.

(3) Alternating Hypertropia.-Upward deviation of either eye obvious in binocular vision on alternating fixation. This is due to paresis of the depressors and to it may be added a degree of hyperphoria.

Whether we consider two or three conditions depends on:

(a) whether " alternate sursumduction " ever occurs without some slight oblique imbalance,

(b) whether overaction of an inferior oblique muscle always can be classed as a sign of past or present paresis.

The author has no notes of a case of alternating hyperphoria without evidence of some vertical imbalance. The non-paretic causes of oblique imbalance are summarized elsewhere (Anderson, 1947). It is claimed that if the very common overaction of one or both inferior oblique muscles be included as "a sign of paresis", then this pure form of sursumduction is very rare.

Consideration of this series suggests that there are but two separate conditions:

(1) Alternating (or occlusion) Hyperphoria (or Sursumduction) in which varying signs of vertical muscle imbalance can be elicited though not visible in frontal binocular fixation,

(2) Alternating (or double) Hypertropia in which signs of paresis are obvious in binocular vision, and to which a degree of " phoria " may be added. 
One other question must be asked. Is the upward deviation, so common in adduction suggestive of an overacting inferior oblique muscle, really due to imbalance or to "occlusion hyperphoria " following the interruption of binocular vision as the nose obstructs the field of the adducted eye? If this were so, surely we should find just as many diagnoses of underaction of the superior oblique muscles on looking down and in? In addition, would there not be a sudden swing as soon as the vision of the adducted eye was obstructed by the nose? As the answers to both questions are negative we can discount this explanation.

Suggested Explanations.-There are three movements to be explained:

(i) Upward rotation of the covered eye.

(ii) Slow movement of both eyes towards the side of the covered eye,

(iii) Slow movement of both eyes away from the direction of conjugate deviation.

On considering the first of these, several ideas present themselves. Does the movement result from:

(a) a return to the position of rest, comparable with Bell's phenomenon,

(b) oblique muscle imbalance,

(c) the release of peripheral fusion,

(d) unequal retinal stimulation, similar to Bielschowsky's phenomenon?

If the movement is simply a return to the true position of rest, why does occlusion of both eyes not lead to double sursumduction? How can the eyes be so dissociated that only one eye rotates upwards?

Light on this problem may come if we consider the control of ocular fixation. It is difficult to explain the manner in which a covered eye follows the movements of its fellow, unless we postulate a monocular conjugate mechanism. This conception is supported by the unilateral cases of latent nystagmus, of which there were five in this series (Cases 16-20). In such cases nystagmus following occlusion of only one eye can be explained, as Verhoeff suggested, on the assumption that there is a conjugate mechanism for each eye. That means two monocular conjugate mechanisms, but these will not explain the more common cases in which horizontal nystagmus occurs on covering either eye, when no horizontal or rotatory nystagmus is present in binocular vision. Verhoeff pointed out that binocular fixation cannot be the main factor, since strabismus is nearly always present and suggested the presence of a binocular conjugate mechanism.

The present series shows that there is, at least in most cases, excessive action of one or both inferior oblique muscles. It will be seen that similar imbalance was found in the majority of eighteen patients with alternating hyperphoria in the absence of nystagmus. In addition extorsion of the covered eye and intorsion as it descended after occlusion was not infrequently noticed. This suggests an oblique imbalance, for in normally balanced upward rotation no torsion is visible. 
The reasons for the frequency of oblique imbalance cannot be considered here. It is of interest however to recall that certain peculiarities of the superior oblique muscle - the characteristics of its course, and of the course of its nerve supply-appearing late in phylogeny make the muscle liable to congenital defects. The nuclear association of the muscle with the homolateral inferior rectus is also of interest.

In eighteen cases of alternating hyperphoria without nystagmus the following defects were found:

Five had unilateral inferior oblique overaction; (three of these had an underacting inferior rectus).

Eleven had bilateral inferior oblique overaction; (three of these had underaction of both inferior recti, one had underaction of one superior rectus, and one had overaction of one superior oblique).

Two had superior oblique overaction and underaction of one inferior rectus, (one of these also had underaction of one inferior oblique).

All but two of the total had convergent strabismus; one of these was esophoric and the other was divergent.

Valuable information comes also from observations of any ocular torsion of the occluded eye that may occur as it rolls up or downwards. As a rule upward rotation is associated with extorsion. This, and the increase of upward rotation on looking towards the uncovered eye, suggests a weakness of the superior oblique muscle. Verhoeff (1941) suspected hypoplasia of the nucleus of the inferior rectus in two unilateral cases, for in them the covered eye showed intorsion and the upward rotation was greatest when looking down and outwards.

It is not claimed that these diagnoses present complete pictures of the defects in each case, but they do show the close relationship between the inferior ocular.muscles and alternating hyperphoria. Verhoeff suggested muscular conjugate insufficiency of a superior oblique muscle as the main cause in many cases, but weakness of a superior oblique muscle was present in some of my cases, and such weakness may be frequently overlooked.

Oblique muscular imbalance is probably an essential factor in the production of alternating hyperphoria. It is also worthy of repetition that the only patient with typical latent nystagmus and no alternating hyperphoria was the only one with normal versions (Case 14).

The frequency of rotatory nystagmus in this series of patients with latent nystagmus is probably due to the high percentage with the same defect.

What force produces recovery in alternating hyperphoria? Is it simply fusion?

For example Case 16 had, with right eye fixing, $-3^{\circ}, L / R$ 21, and with left eye fixing $-4^{\circ}, \mathrm{R} / \mathrm{L} 22$. Visual acuity was $6 / 9$ partly in the right eye, and $6 / 5$ in the left. The patient had only "momentary fusion without range". Away from the synoptophore her eyes appeared straight. The right eye did rotate up at times but could be brought straight again at will. 
Fusion was considered to be absent in twelve of 23 patients with alternating hyperphoria without nystagmus. Correspondence was either absent or abnormal in six of these. Is it peripheral fusion then that holds the eyes parallel in binocular vision or produces recovery after occlusion? If fusion is so essential, why does not upward rotation occur in its absence apart from monocular occlusion?

The withdrawal of "fusion" that permits the unveiling of alternating hyperphoria may be a factor in some cases. The existence, however, of two monocular and one binocular conjugate mechanism as the foundation on which the fixation reflex is built appears to be a reasonable assumption.

It is possible that an arrested development of one or other of these may occur as a result of some disorder at birth. The subsequent revelation of an existing oblique imbalance would then become the essential cause of alternating hyperphoria.

How then can we explain the latent nystagmus that becomes manifest on occlusion? It appears that the withdrawal of retinal stimulation, by occlusion and other means, produces a slow movement towards the covered eye. If the tone of the horizontal rotators is not correctly balanced, a fast recovery and rhythmic nystagmus will supervene. Now, as withdrawal produces this effect, it is reasonable to assume that the stimulation that has been withdrawn had been causing the opposite movement previously. That is, a sharp image on one macula causes a slow deviation towards the opposite side-the opposite effect of withdrawal (Kestenbaum, 1946). Such stimulation reaching each eye at the same time may explain normal parallelism and throw some light on convergence.

Variations in the efficiency of certain stimuli and the presence of latent nystagmus with unilateral cataract make one doubtful that this explanation alone is adequate.

We have seen that at least half of the patients in this series had some difficulty at birth. It is significant too that almost one-third of the mothers concerned did not have a second labour, and that another third had but one more child.

It is suggested that it is reasonable to associate delay and difficulty at birth with these defects, for they depend on the development of a complex system of reflexes, which probably does not reach maturity until term or soon afterwards since demands are not made on it until some months after birth.

Measurement.-In alternating hyperphoria the orthoptist has many problems, the main one being the variation in the measurements obtained. Considerable study of each patient is necessary, and the information that is essential for the surgeon can be gained as a rule by the following tests:

(1) Measurement of the relative positions of the eyes when looking into the distance in the absence of any slides in the synoptophore, the orthoptist relying on corneal reflexes. 
(2) Measurement of the angle chosen for fusion of suitable slides.

(3) Measurement of the angle chosen for simultaneous perception with each eye fixing alternately.

The influence of adduction and abduction may reveal the presence of oblique muscle imbalance. This should be looked for with each eye at $-15^{\circ}$ and $+15^{\circ}$. These measurements should reveal:

(1) position of eyes at rest,*

(2) influence of fusion,

(3) degree of alternating hyperphoria.

Treatment.-Since the defect is not manifest in binocular vision it calls for little treatment. Accurate correction of refraction and possibly the training of fusion are indicated. An operation may be indicated for the imbalance that exists with the hyperphoria. Before this is carried out careful measurements and possibly photographs are essential.

\section{Conclusions}

Analysis of so small a series as this paper presents can permit the drawing of only tentative conclusions. As such the following may be of value:

(1) Latent nystagmus may be regarded as an entity. It shows variations, but is characterized by its appearance on occlusion of either eye. In addition, in some cases, the nystagmus at times may be constant. Such cases merge with the small group with constant nystagmus which increases on occlusion.

Variants of any so-called typical condition are usually discovered by careful observations of its appearances.

(2) As with experimental vestibular nystagmus, the exciting agent appears to be asymmetrical stimulation of distance receptors, but the former condition is physiological, whereas latent nystagmus arises from a disordered basic mechanism.

(3) With one exception, every case of latent nystagmus in this series showed alternating hyperphoria. Both conditions can be increased by nervous tension and fatigue.

(4) The nystagmus on occlusion is nearly always rhythmic, with the initial slow component towards the covered eye. The nystagmus that occurs on conjugate deviation is frequently rotatory; when it is rhythmic the slow component is away from the direction of gaze.

(5) The rotatory form of nystagmus is probably due to oblique muscle imbalance.

(6) Alternating hyperphoria, in the author's experience, is always associated with signs of imbalance of the oblique and sometimes of the rectus muscles. It may be added to the obvious vertical defects of alternating or double hypertropia. A study of versions and of any ocular torsion as the covered eye rotates upwards or downwards reveals the nature of the imbalance.

(7) The term "alternating sursumduction" has been used for the upward rotation of either eye on alternate occlusion in the absence of " any obvious signs of paresis ". If imbalance of the oblique muscles is included as such a sign, the author is not familiar with any such condition of "alternating sursumduction". *It may not be possible to estimate the true position of binocular rest by a machine that depends on the separation
of the vision of one eye from that of its fellow. 
(8) It is suggested that latent nystagmus and alternating hyperphoria may be due to arrested development of the oculomotor mechanisms that underlie binocular fixation. Their full elaboration may be prevented at any early stage in development when they are vulnerable.

(9) It is suggested that difficulties at birth, which were very common in this series of patients, may cause both these conditions. No evidence of inheritance was observed in this series.

(10) All the patients in this series and the great majority in the literature were under 35 years of age. Latent nystagmus appeared to grow less with age in some patients, but no diminution of alternáting hyperphoria was observed.

\section{Comment}

The usefulness of the title "latent nystagmus" for the condition under discussion may have passed. In a wide sense many forms of nystagmus exist that may be described as latent. Some are physiological, but others are not, for they reveal an abnormality of some neurological mechanism. The optico-kinetic form may be regarded as a physiological latent nystagmus. So may that following vestibular or acoustic stimulation. Occasionally forcible opening of closed eyelids, or sudden backward jerking of the head and conjugate movements of the eyes, or, as we have seen, obstruction of the vision of one eye, may produce nystagmus, provided an underlying sensori-motor mechanism is disordered.

The author wishes to express his thanks to the orthoptists Miss J. Burns-Priddle and Miss $\mathbf{M}$. Jacobs for their help with this paper. He is grateful also to Dr. T. E. Lowe, Director of the Baker Institute, Alfred Hospital, and to Mr. Thomas O'Connor, photographer to this hospital for the photographic work that assisted this investigation.

\section{REFERENCES}

ANDERSON, J. Ringland (1947). “Ocular Vertical Deviations". (British Journal of Ophthalmology. Monograph Suppl. 12).
(1948). British Journal of Ophthalmology, 32, 653.

HOEVE, J. VAN DER (1918). Ned. T. Geneesk., 1, 790. Cited by Sorsby (1931).

KestenBAum, A. (1946). "Clinical Methods of Neuro-Ophthalmologic Examination ", p. 236. Grune and Stratton, New York.

LANCASTER, W. B. (1950). "Strabismus, Ophthalmic Symposium" (1), ed. J. H. Allen, p. 162. Mosby, St. Louis.

SCOBEe, R. G. (1952). "The Oculorotary Muscles", 2nd ed., p. 183. Mosby, St. Louis.

SORSBY, A. (1931). British Journal of Ophthalmology, 15, 1.

VERHOEFF, F. H. (1941). Arch. Ophthal. (Chicago), 25, 780. 